\title{
Democracia vs. crecimiento económico: ¿quién fue primero, el huevo o la gallina?
}

| Fecha de recibido: 28 de abril del 2020 | Fecha de aprobación: 19 de septiembre del 2020 |

Rodrigo Mezú

Magíster en Ciencia Política

Fuerza Aérea Colombiana Grupo de Investigación Análisis en Contexto Rol de investigador: teórico y escritura https://orcid.org/0000-0002-4690-3307

$\triangle$ r.mezu10@uniandes.edu.co

Cómo citar este artículo: Mezú, R. (2020). Democracia vs. crecimiento económico: ¿Quién fue primero, el huevo o la gallina?. Revista Ciencia y Poder Aéreo, 15(2), 18-31. https://doi.org/10.18667/cienciaypoderaereo.660 


\section{Democracia vs. crecimiento económico: ¿quién fue primero, el huevo o la gallina?}

\section{Democracy vs. Economic Growth: Which Came First, the Chicken or the Egg?}

\section{Democracia $x$ crescimento econômico: Quem veio primeiro, a galinha ou o ovo?}

Resumen: por mucho tiempo se ha enseñado en las aulas de clase que el mejor remedio para el desarrollo económico es la fortaleza democrática. En ese sentido, entre mayores libertades sociales mayor sería la oportunidad en el crecimiento de una nación. No obstante, con el rápido desarrollo de los tigres asiáticos, donde la democracia no es el común denominador, la visión del desarrollo se volcó, no necesariamente a la fortaleza democrática sino también a la estructura de las instituciones. Aunque la democracia podría seguir siendo el ingrediente principal para lograr ese anhelado y occidentalizado desarrollo económico (Lipset, 1959a,b), no necesariamente es la única variable por considerar para determinar tal avance; más bien, el tipo de instituciones ayudan a establecer incentivos y crear mejores condiciones para alcanzar ese "despegue" en lo político y lo económico. De ahí que, la democracia, en el largo plazo, permitiría abrir el paso al desarrollo, no sin desconocer la importancia de la historia en cada país, lo que al final determina las propias singularidades de su desarrollo.

Palabras clave: crecimiento económico; democracia; desarrollo; instituciones políticas y económicas.

Abstract: It has long been taught that democratic strength is the best remedy to gain economic development. In that sense, the broader the social freedoms, the greater the opportunities for the growth of a nation. However, with the rapid development of the Asian tigers, where democracy might not be the common denominator, this vision of development turned not only toward democratic strength but to the structure of institutions as well. Although democracy could remain as the main ingredient to achieve this longed-for and westernized economic development (Lipset, 1959a, 1959b), it is not necessarily the only variable to determine such progress; rather, is the type of institution what becomes essential in establishing incentives and creating better conditions to achieve a political and economic "take-off" of this kind. Hence, democracy, in the long term, would allow opening the way to development, although not without ignoring the importance of history in each country, which in the end determines singularities for the development of nations.

Keywords: Economic growth; democracy; development; political and economic institutions.

Resumo: Por muitos anos foi ensinado nas aulas de clase que o melhor remedio para o desenvolvimento econômico é a fortaleza democrática. Nesse sentido, quanto maiores são as liberdades sociais, maiores são as oportunidades de crescimento de uma nação. No entanto, com o rápido desenvolvimento dos tigres asiáticos, onde a democracia não seria o denominador comum, a visão de desenvolvimento voltou-se não necessariamente para a fortaleza democrática, mas também para a estrutura das instituções. Embora a democracia pudesse continuar sendo o ingrediente principal para alcançar o almejado e ocidentalizado desenvolvimento econômico (Lipset, 1959a/b), não é necessariamente a única variável a ser considerada para determinar esse progresso; pelo contrário, o tipo de instituções ajuda a estabelecer incentivos e criar melhores condições para atingir essa "decolagem" política e econômica. Deste modo, a democracia, ao longo prazo, permitiria abrir caminho ao desenvolvimento, não sem desconhecer a importância da história em cada país, o que no final acaba determinando as próprias singularidades no seu desenvolvimento.

Palavras-chave: Crescimento econômico; Democracia; Desenvolvimento, Instituições Políticas/econômicas. 
Un sistema democrático no promueve, per se, el progreso económico, social y político en una nación. Existe una serie de factores que establece las condiciones que permiten generar un salto hacia adelante. Por ello, el camino para llegar al desarrollo económico es variado, por ejemplo, países como Estados Unidos, Inglaterra, Francia, entre otros, lo han hecho sustentados en un sistema democrático liberal; en tanto, otros casos como Corea del Sur (en sus inicios), China y Singapur, lo han hecho montados en regímenes que pueden considerarse de corte autoritario. No obstante, tanto los ejemplos con sistemas democráticos como los de corte más autocrático ya mencionados, tienen en común el haber creado instituciones inclusivas ${ }^{1}$ en lo político, lo económico y lo social, las cuales, a su vez, han generado condiciones estructurales favorables al desarrollo económico.

Lo anterior nos incita a preguntarnos: ¿cuál es la relación entre la democracia y el crecimiento económico en un país? Y ¿Qué es más importante, lo político o lo económico? Un ejemplo de la complejidad que implica la relación entre desarrollo económico y democracia se encuentra en los planteamientos de Max Weber, quien

ha argumentado que los factores que explican la democracia son una concatenación de elementos históricamente única [...]. Según el argumento básico, el desarrollo económico capitalista (fomentado y desarrollado al máximo en las zonas protestantes) creó una clase burguesa, cuya existencia fue a la vez un catalizador y una condición necesaria para la democracia (Lijphart, 2001, p. 47)

De este modo, se produjo una alianza entre burguesía y corona que gradualmente facilitó el surgimiento y la legitimación de sistemas democráticos. Por tanto,

1 Acemoglu \& Robinson (2012) clasifican las instituciones en inclusivas y excluyentes. Cada una adquiere rasgos particulares según su configuración política. Para los autores, en el caso de las instituciones inclusivas, las leyes y normas diseñadas por una clase política ayudan a generar las mejores condiciones para el desarrollo económico de una nación. En cambio, cuando los arreglos legales solo benefician a un grupo en particular de la sociedad, estas instituciones adquieren el nombre de extractivas y, en el mediano o largo plazo, resultan en la creación de grandes oligopolios, desventajas al emprendimiento y la innovación. parece que la interrelación generada por "desarrollo económico, protestantismo, monarquía, cambio político gradual y legitimidad" (Lijphart, 2001, p. 49) generó las condiciones para el desarrollo de las democracias.

Con base en ello, la afirmación sobre la relación entre democracia y desarrollo económico es no concluyente, sin desconocer que el mejor sistema, al menos en occidente para garantizar derechos políticos, económicos, sociales y culturales de la población, corresponde a regímenes democráticos liberales (Rhoden, 2015). De ahí que, el argumento de esta investigación va encaminado a demostrar que el diseño de las instituciones, más que la democracia per se, es el factor dinamizador del desarrollo económico de muchos países; esto, sin negar que la democracia también podría ayudar a mejorar las condiciones de vida en términos económicos. Para resolver la inquietud de la precedencia entre democracia y crecimiento económico, se hará una revisión de fuentes académicas, tanto históricas como teóricas, relacionadas con la economía política internacional y la política comparada. En este artículo se hizo un análisis documental para encontrar la respuesta a esa inquietud y, si es el caso, determinar cuán importante es la democracia en el logro de ese objetivo económico, en un mundo que ha visto cómo regímenes poco democráticos sacan de la pobreza a sus ciudadanos. En ese orden de ideas, el documento se ha divido en dos partes. En la primera, se definen los conceptos de democracia, desarrollo económico y se explica a grandes rasgos cómo se entrelazan uno con el otro, a partir de la exposición de los planteamientos de diversos autores que han abordado este tema. En la segunda, se profundizará en la relación e interacción que existe entre las instituciones, la democracia y el desarrollo económico.

\section{Definiciones sobre democracia, crecimiento económico y sus principales autores}

Una definición minimalista y delimitada sobre democracia es la que hacen Preworski et al. (1995), en la cual 
aseguran que consiste en un sistema en el que algunos partidos ganan y otros pierden. De acuerdo con lo planteado por Linz \& Valenzuela (1994), la democracia se resume en gobierno de tipo transitorio, en el cual los conflictos se dan por superados según algunas normas escritas o no, pero que en todo caso, siempre son acordadas o prestablecidas entre las partes.

Aquí es donde el crecimiento o desarrollo económico se abren paso, son muchos los autores que empíricamente han logrado demostrar el vínculo existente entre democracia y desarrollo económico, sin desconocer otras variables como la fortaleza de las instituciones, la educación, el contexto histórico (path dependence), las coyunturas críticas, los tipos de diseño institucional, entre otros.

Con respecto al crecimiento económico, Feng (1997) lo define como la tasa de crecimiento del PIB real, dato que se obtiene del análisis de variables de tipo económico como son el capital humano, su acumulación, y la inversión sumada al crecimiento o expansión del mercado. Para complementar la definición de Feng, Baum \& Lake (2003) consideran otras variables como el ingreso familiar, el crecimiento de la población y la inversión de capital humano.

Con base en lo planteado, en el debate sobre la democracia y el crecimiento económico se pueden identificar tres vertientes relacionadas, el primer grupo está liderado por Lipset (1959a,b; 2001), Sirowye \& Inkeles (1990), Helliwell (1994) y Heo \& Tan (2001), académicos que identifican un efecto positivo entre la democracia y el crecimiento económico, un pensamiento que también guía a Huntington (1970) y Krieckhaus (2006), a pesar de que ellos encuentran una relación de tipo negativa. Así mismo, dentro de este grupo se encuentra a Barro (1996), quien determina que la relación entre democracia y crecimiento económico no es lineal; de ahí, que a mayores niveles de democracia el crecimiento aumenta hasta cierto punto desde el cual disminuye, así la democracia siga aumentando. En esta primer vertiente, las instituciones políticas determinan el tipo de instituciones económicas, por lo que ambas instituciones, no necesariamente definen el aumento o disminución de la democracia, pero sí un fortalecimiento del crecimiento económico. Sobre este tema se profundizará más adelante a través del trabajo de Acemoglu \& Robinson (2012).

Para este primer grupo de teóricos, la democracia por sí sola no encuentra el crecimiento de una economía, ya que aseguran que deben existir otro tipo de variables independientes que sumadas permitan que, de acuerdo con la democracia, el crecimiento económico de un país se genere. Por ejemplo, Lipset (2001) resalta el papel que tiene el nivel de instrucción, pues a mayor nivel "es más probable que se crea en valores democráticos y se apoyen prácticas democráticas" (p. 49) y respalda esta afirmación al señalar que "los estudios pertinentes indican que la instrucción es un factor mucho más significativo que la renta o la ocupación" (Lipset, 2011, p. 50). Por tanto, la educación es una condición necesaria, aunque no suficiente, para el desarrollo de una democracia. De modo que el desarrollo económico está supeditado al emprendimiento, la educación y la promoción de la libertad económica, lo que indica que un alto grado de crecimiento económico tiene la capacidad de aumentar su nivel de educación, así como los ingresos de los ciudadanos y la renta nacional. Por ese motivo, aumentará la demanda de muchas políticas que mejoren el bienestar, incluida la gama de derechos políticos, sociales y libertades civiles, y, eventualmente, el país mejorará su nivel de democracia (Helliwell, 1994; Heo \& Tan, 2001). En opinión de Lipset (2001) "el desarrollo económico, que significa una renta superior, una mayor seguridad económica y una mayor instrucción, permite que los estratos más bajos adopten planteamientos temporales a más largo plazo y criterios políticos más complejos y graduales" (p. 51). Esta corriente representa la visión, en momentos errada, sobre la democracia y la base para el desarrollo económico de algunos Estados. Pese a su propuesta, este grupo de académicos parece dejar de lado otras variables como el path dependence y el tipo de instituciones.

Para el segundo grupo de académicos, la democracia y el crecimiento económico poseen una fuerte relación mediada por el capital humano, la estabilidad política, la calidad y el tamaño del gobierno de turno, la inequidad en el ingreso, la apertura comercial, la acumulación de capital e inversión, entre otros. 
Convirtiéndola en una relación de tipo econométrico, defendida principalmente por Cheibub et al. (1996), aunque vale mencionar que después, en el 2004, Przeworski encuentra poca relación entre estas.

Desde un enfoque basado en la teoría de la modernización, Adam Przeworski et al. (2000) en el texto titulado, Economic Development and Political Regimes, se preguntan: ¿Cuáles son las condiciones que determinan la prevalencia de una democracia o de una dictadura?, ¿qué causa que los regímenes políticos asciendan, perduren o caigan? Para responder, plantean una serie de explicaciones sobre la relación existente entre desarrollo económico y democracia, ya que para ellos la incidencia entre ambas es alta.

Al emplear herramientas cuantitativas, los autores encuentran que el nivel de desarrollo económico, medido por el ingreso per cápita, es el mejor predictor de los regímenes políticos. Con todo, hay países en los que las dictaduras persisten aun cuando todas las condiciones observables indican que no deben, hay otros en los que las democracias florecen a pesar de todas las probabilidades. Así, algunos factores que influyen en la incidencia de los diferentes tipos de regímenes no se identifican en este análisis (Przeworski et al., 2000).

Para los autores hay dos razones distintas que explican el hecho de que la incidencia de la democracia puede estar relacionada con el nivel de desarrollo económico, pues "las democracias pueden ser más propensas a surgir en los países que se desarroIlan económicamente; o, habiendo sido establecidas por cualquier razón, las democracias pueden ser más propensas a sobrevivir en los países desarrollados" (Przeworski et al., 2000, p. 39).

La teoría de la modernización considera que cuando un país se desarrolla económicamente las estructuras sociales se transforman, llegan a ser más complejas, por lo que la sociedad civil se opone al régimen haciendo que este caiga como resultado de una sociedad lista para la democratización. De ahí que la modernización pueda ser una razón importante de la relación entre la incidencia de la democracia y el desarrollo económico (Przeworski et al., 2000). Con todo, “solo pocos casos de 'ensueño' corroboraron esta afirmación, Brasil, Checoslovaquia, Portugal, quizás Corea del Sur y Grecia, ya que estos se desarrollaron bajo dictaduras y llegaron a ser ricos, y sus dictaduras cayeron más o menos cuando sus niveles de desarrollo lo predijeron [...]. La modernización puede crear los 'prerrequisitos' para el conflicto político en torno a la forma del régimen, pero el modo en que esos conflictos se desarrollan permanece impredecible" (Przeworski et al., 2000, p. 51).

Przeworski et al. (2000) reconocen las limitaciones de su explicación, y aclaran que el desarrollo económico no es la única causa que explica la caída de una dictadura y el ascenso de la democracia. El desarrollo económico parece desestabilizar a las dictaduras en países con un nivel intermedio de ingresos ( $\$ 1.001$ a \$4.000USD / \$4.001 a \$7.000uSD), pero no en aquellos que son de bajos recursos ni en los que son ricos (Przeworski et al., 2000). No obstante, se presentan una serie de anomalías que permiten concluir que el poder causal del desarrollo económico en la reducción de las dictaduras parece insignificante. El nivel de desarrollo, por lo menos según lo medido por el ingreso per cápita, da poca información sobre las posibilidades de transición a la democracia, aunque de otro lado, el ingreso per cápita parece tener un fuerte impacto en la sobrevivencia de las democracias Przeworski et al. (2000); Kailitz (2013); Norris \& Coma (2014).

Por último, el tercer grupo asegura que no hay ninguna relación sistemática entre la democracia y el crecimiento económico. De manera que, mientras para Feng (1997) la estructura institucional y las estrategias de desarrollo del gobierno son más importantes, Helliwell (1994), Nelson \& Singh (1998) no encontraron ningún impacto estadístico sobre el crecimiento económico en algunos países estudiados de Latinoamérica y África.

Retomando a Seymour Lipset, a partir de 1959 el autor identifica que los países más democráticos son, coincidentemente, los más prósperos y por eso su análisis se hace sumamente interesante. Su hipótesis, que más tarde es puesta a prueba por Barro (1996), asegura que la democracia está relacionada con el estado del desarrollo económico. Esto significa que cuanto más adinerada sea una nación, mayores serán 
las posibilidades de que se mantenga bajo un sistema democrático. En su artículo, Lipset (1959b) planteó la hipótesis de una serie de procesos históricos y sociológicos por los cuales el desarrollo generó una mayor aproximación a la democracia. Para él, el desarrollo económico produce o facilita la democracia solo en la medida en que altera de manera favorable cuatro variables importantes que intervienen, a saber: cultura política, estructura de clase, relaciones estado-sociedad y sociedad civil.

Esta hipótesis de Lipset (1959b) no solo es corroborada por Barro (1996), sino que además encontró lo siguiente:

1. Los aumentos en diversas medidas del nivel de vida tienden a generar un incremento gradual de la democracia.

2. En los casos estudiados, solo Corea del Sur y Taiwán se convirtieron en democracias después de las reformas económicas, mientras tanto China, Singapur y Vietnam aún no. Sin embargo, su teoría predice que estos países en algún momento serán democráticos.

3. La revisión de los datos entre países sugiere que aquellas naciones con bajos niveles de desarrollo económico tienden a no sostener la democracia.

4. Las mejoras en el nivel de vida, medido por el PIB de un país, la tasa de mortalidad infantil y el logro de la escuela primaria, aumentan la probabilidad de que las instituciones políticas se vuelvan más democráticas con el tiempo.

Otros teóricos como Olson (1945), Moore (1966), Needler (1968), Haggard (1990), Leblang (1996), Londregan \& Poole (1996), Przeworski (2004), Wade (2004), Monroy\& Flores (2009), Acemoglu \& Robinson (2000; 2012; 2014), Acemoglu et al. (2015) y Lipset (2016; 2001), aseguran que ciertas variables, entre ellas la educación, permiten un mejor acople en este vínculo entre democracia y desarrollo económico. Además, tanto el diseño institucional, como la historia, en especial la relacionada con el legado colonial y la centralización estatal, ayudan a que la democracia logre tal desarrollo económico. Por ejemplo, en el caso de
Latinoamérica, históricamente se ha presentado una debilidad e inequidad en la aplicación de las leyes. Algunos autores han planteado que esta debilidad tiene su origen en el legado colonial y en sus instituciones extractivas (Acemoglu et al., 2001; Acemoglu \& Robinson, 2014), o en las instituciones excluyentes que instauraron las élites oligárquicas en el siglo xIx, las cuales en lo jurídico establecían igualdad, pero en la práctica condiciones de exclusión e inequidad (Sáinz, 2019). En sintonía con lo anterior, Lipset señala que "los estratos superiores también tienden a considerar los derechos políticos de los estratos inferiores, especialmente el derecho a participar en el poder, como algo básicamente absurdo e inmoral" (2001), así que, "los estratos superiores no sólo se oponen ellos mismos a la democracia, sino que su conducta política, frecuentemente arrogante, ayuda a intensificar reacciones extremistas por parte de las clases más bajas" (Lipset, 2001).

Por su parte, Haggard \& Kaufman (2008) en su trabajo comparado de América Latina, Asia Oriental y Europa del Este, miden la evolución del estado de bienestar entre 1945 y el 2005, como Acemoglu et al. (2019) en sus resultados se evidenciaron que estas regiones no respaldan la opinión de que la democracia se convierte en un obstáculo para el crecimiento económico, por debajo de cierto umbral de desarrollo. Empero, encontraron variados efectos por el nivel de educación, lo que sugiere que la democracia tiene efectos más positivos para las economías con una mayor fracción de la población con escolaridad (secundaria). El planteamiento anterior, coincide con lo señalado por Lipset (2001). Así, los países de Asia Oriental aumentaron la inversión en educación, durante 1945 y el 2005 lograron sobrepasar otras regiones como Latinoamérica, y este caso en particular, es un ejemplo de la evolución de una sociedad debido a sus instituciones políticas inclusivas (Haggard \& Kaufman, 2008).

Así, la educación provee respuestas adicionales al desarrollo de los Estados y, sin ir muy lejos, la humanidad es testigo de cómo algunos países asiáticos han logrado desarrollarse mediante una estrategia alejada del sistema democrático en sistemas centralizados, jerárquicos y acogidos a su larga historia meritocrática. Por ejemplo, en el caso de Corea del Sur, cuya 
disciplina fiscal, sumada a otros factores, entre ellos la capacitación a su población en temas tecnológicos y la abrumadora disciplina en la persecución de sus metas, han contribuido a una rápida modernización que se ha reflejado en su desarrollo económico y el aumento de su democratización. Estas naciones lograron un acelerado desarrollo económico, alejados del consenso o luchas partidistas que ofrece la democracia; ello les permitió salir de la pobreza y aumentar el poder adquisitivo de sus ciudadanos, la movilidad social y un PIB mucho más alto.

Desde otro ángulo, Przeworski (2004) asegura que las democracias no son comunes en países con un PIB bajo (población de bajos recursos), y sí muy recurrentes en países adinerados. Ello lo demuestra a través de una investigación realizada durante medio siglo entre 1950 y 1999, en la que recolectó más de 1.300 observaciones anuales sobre países con ingresos per cápita menores a los $\$ 2.000$ USD, observación que cubrió a un total de 142 democracias. De las 880 observaciones anuales de países con ingresos superiores a \$8.000usD, solo 147 pasaron bajo dictaduras. De hecho, si se toma solo el ingreso per cápita, se predecirá correctamente el $75 \%$ de las 5.179 observaciones anuales de regímenes (Przeworski, 2004).

En ese sentido, se puede asegurar que de acuerdo con los postulados hechos por la teoría de la modernización, en la medida en que los países con menos riqueza van aumentando su PIB y salen de la situación de pobreza, sus sistemas se tornarían democráticos. No obstante, es posible que muchas democracias surjan en países de escasos recursos sin haber avanzado económicamente. Eso sí, Przeworski (2004) asegura que si un país en estado de precariedad logra democratizarse al cabo de 20 años aproximadamente, su PIB será mayor que aquellos en igualdad de condiciones sin fortaleza democrática.

La observación más general es que las transiciones a la democracia ocurren según una amplia variedad de condiciones, mientras que las transiciones a las dictaduras exhiben patrones bien definidos (Przeworski, 2004). Otra forma de decirlo, es que es fácil predecir estadísticamente si una democracia sobrevivirá, y es casi imposible predecir si se establecerá una. En promedio, las dictaduras tienen casi la misma probabilidad de sobrevivir cuando sus economías crecen, que cuando disminuyen durante el gobierno de uno, dos o tres años consecutivos. Es decir, algunas dictaduras cayeron después de varios años de crecimiento, mientras que otras murieron después de varios años de declive económico.

\section{Relación entre las instituciones, la democracia y el desarrollo económico}

Según Acemoglu \& Robinson (2014), los países desarrollados tienen mayores beneficios económicos debido a las "instituciones económicas inclusivas" que desarrollaron. Dichas instituciones, son una combinación del Estado y del libre mercado en el cual:

1. El Estado crea incentivos para que las personas inviertan e innoven, garanticen los derechos de propiedad privada y hagan cumplir el derecho contractual.

2. El Estado permite la inversión y el crecimiento a través de la educación y la infraestructura.

3. El Estado está controlado por sus ciudadanos, en lugar de estar monopolizado por una pequeña élite. Crucialmente, debe haber un principio democrático en el trabajo, en el cual las personas en la política establezcan instituciones y leyes que funcionen para la mayoría de individuos, en lugar de trabajar solo para beneficiar a los ricos.

4. El Estado debe mantener el monopolio de la violencia como lo asegura Tilly (2017).

Las instituciones económicas inclusivas se dan paso gracias a instituciones políticas lo suficientemente centralizadas y pluralistas. Estas instituciones permiten generar una cantidad de leyes que favorecen la libre competencia, cortan el avance de los monopolios y oligopolios, y evitan que, por ejemplo, empresarios con mucho poder económico legislen en favor 
de sus intereses comerciales. Unas instituciones políticas inclusivas evitarían que personas del corte del empresario Sarmiento Angulo, dueño de la red bancaria más grande del país, haya monopolizado la banca colombiana ${ }^{2}$, sin antes haber confrontado fuertes oposiciones políticas. Aunque en su caso, encontró instituciones políticas extractivas que, en cierta forma, le han permitido legislar a su favor (Carrero-Barón, 2013).

De otra parte, las instituciones políticas extractivas tienden a concentrar su poder en manos de una pequeña élite. Lo cual lleva a la fijación de tener muy pocos límites en el ejercicio de su poder, y terminan promoviendo sus intereses mediante la captura del Estado y sus instituciones. Por lo general, las instituciones económicas se estructuran según el deseo de esta pequeña élite para, como su nombre lo indica, extraer recursos de la sociedad en general. Como resultado, las instituciones económicas extractivas por antonomasia, acompañan naturalmente a las instituciones políticas inclusivas, por lo que dichas instituciones económicas existen gracias a las políticas extractivas creadas por esa élite. Algunos ejemplos de instituciones económicas extractivas, diseñadas por políticas de este tipo en diferentes lugares, fueron la esclavitud en los Estados Unidos ${ }^{3}$, Barbados ${ }^{4}$, gran parte de África colonial ${ }^{5}$, y el Decreto 177 de Guatemala, que obligaba al trabajo forzado y gratuito de la población indígena a expensas de los terratenientes.

A pesar de que estas instituciones económicas extractivas pueden generar crecimiento a corto plazo, resultan en escasez a largo plazo. Por ejemplo, los

2 Esta reflexión nace a partir del artículo "Una fortuna hecha sobre el sudor y lágrimas de los colombianos”, de Anhy Durley González Durán, publicado en el portal de análisis político colombiano Las2Orillas.

3 La esclavitud en los Estados Unidos existió durante los siglos XVII, XVIII y XIX, fue la institución legal de la esclavitud humana de chattel, ejercida a los africanos y afroamericanos.

4 En 1826, la legislatura de Barbados aprobó la Ley de Esclavos, que simultáneamente otorgaba concesiones a los esclavos y brindaba garantías a los propietarios de estos. Una tercera parte de la población blanca terminó esclavizando a dos terceras partes de la población negra. Finalmente, la esclavitud fue abolida por el Imperio Británico 18 años después, en 1834.

5 La esclavitud para fines domésticos y judiciales fue generalizada en toda África. En las plantaciones de la costa oriental de África y en partes de África occidental. La importancia de la esclavitud en las plantaciones domésticas aumentó durante el siglo xIx debido a la abolición de la trata de esclavos en el Atlántico. españoles después de haber llegado por equivocación a tierras americanas, fundaron instituciones extractivas destinadas al saqueo de los recursos minerales (principalmente plata), lo cual generó un boom en el crecimiento económico de España, aunque los recursos extraídos terminaban en los Países Bajos o en Inglaterra. Estas instituciones extractivas hicieron uso de la mano de obra indígena, así como de la esclavitud, explotaron sus riquezas y dejaron un legado colonial (path dependence) de instituciones extractivas formales e informales.

Dicho esto, se ha creado un "círculo vicioso" en muchos países en vía de desarrollo en los últimos tres o cuatro siglos. Las instituciones extractivas fueron establecidas por primera vez por una potencia colonial (construida sobre instituciones extractivas internas ya existentes, como el caso del sanguinario Rey Leopoldo II, en Bélgica, con la República del Congo), que se volvió aún más extractivo bajo los gobernantes poscoloniales. Lo cual, a su vez, condujo a una guerra civil en donde las facciones competidoras lucharon por el control de las instituciones extractivas, generando un espiral de caos de Estados fallidos.

En lugares donde hubo tal oposición anticolonial (contra los españoles), como en Río de la Plata, Argentina, o en el asentamiento de Jamestown, Estados Unidos (contra los británicos), las dinámicas de desarrollo dieron paso a otro tipo de relación y, por lo tanto, a diferentes tipos de instituciones políticas, en su mayoría inclusivas. Según Acemoglu \& Robinson (2012), dicho legado perdura hasta nuestros tiempos, cuando vemos un arraigo corrupto y elitista en muchas excolonias españolas latinoamericanas, y una prevalencia de las instituciones políticas inclusivas. Estados Unidos es uno de los ejemplos más cercanos del funcionamiento de las de instituciones políticas inclusivas, su penosa historia esclavista y, más adelante, segregacionista, agrupadas de acuerdo con las leyes del tipo Jim Crow $^{6}$ pudieron ser eliminadas según estos arreglos institucionales.

6 Fueron leyes estatales y locales que impusieron la segregación racial en el sur de los Estados Unidos. Todas fueron promulgadas a finales del siglo XIX e inicios del XX, por las legislaturas estatales dominadas por 
En contraste, y por varios siglos, países desarrollados como Estados Unidos y Reino Unido, se han beneficiado de lo que se denomina el círculo virtuoso en el que las instituciones se han vuelto gradualmente más inclusivas, ello ha creado incentivos crecientes para los empresarios y el crecimiento económico. Acemoglu y Robinson (2012) llegaron a esta conclusión por medio de una serie de estudios comparativos entre países que están muy cerca geográficamente: México y Estados Unidos; Corea del Sur y Corea del Norte; Botswana y Zimbabwe. Los autores argumentan que la diferencia crucial entre estos países son las infraestructuras institucionales que se han establecido a lo largo del tiempo, lo que a la vez explica su relativo desarrollo o subdesarrollo.

A pesar de ello, no necesariamente ese círculo virtuoso explica el desarrollo de unas naciones y el fracaso de otras. Hay un tema de path dependence relacionado con la forma como se logró la colonización en algunos de estos ejemplos, puesto que, mientras los colonizadores españoles, portugueses y franceses usaron la regla directa o la explotación de sus colonias de mano de uno de los suyos, los británicos usaron la asimilación proporcionando a los colonizados la "oportunidad" de aprender a liderar o administrar su propia gente (Bayart, 2000). La corona española llegó a conquistar y reproducir su mundo en América mediante la centralización, mientras que el colonialismo inglés (para el caso de las 13 colonias), estuvo a cargo de la corona, de empresas privadas y de personas que huían de la persecución religiosa (pacto del Mayflower), con la idea de crear un nuevo mundo. Motivo por el que para los colonos ingleses el principio de autorepresentación era tan importante.

De igual forma, aun cuando existe una pisca de idilio en la afirmación anterior, son muchos los ejemplos donde las colonias británicas están sumidas en la violencia y en condiciones de atraso político y económico, dado que hubo diferencias en la forma de

demócratas blancos después del período de Reconstrucción, las leyes tuvieron vigencia hasta 1965. El Movimiento de Derechos Civiles, liderado por Martin Luther King Jr., tuvo un papel sobresaliente en la visibilización y posterior eliminación de este compendio de leyes retrógradas. llegada y salida de dichas colonias. Además, si bien es cierto que la fortaleza institucional es válida en la argumentación de Acemoglu \& Robinson (2000; 2012), no se pueden desconocer otras variables como aquella de tipo colonial y, por qué no, reconocer que ha habido un fortalecimiento económico de estos países desarrollados a expensas de los países de escasos recursos o menos desarrollados. Así lo plasmaron Cardoso y Faletto (1979) en su teoría de la dependencia, cuando hablaron de las relaciones asimétricas que se presentan entre el centro, la semiperiferia y la periferia.

Por tanto, el mantenimiento y reproducción del legado colonial, así como la instauración de economías con instituciones políticas y económicas extractivas, generan un círculo vicioso del subdesarrollo. A su vez, la ausencia de políticas públicas tendientes a generar condiciones de educación inclusiva, producen una espiral de rezago social y atraso tecnológico que, a la postre, determinan las condiciones de bienestar en un país.

Adicional a lo anterior, estos Estados al no tener un recurso natural intensivo para su explotación, utilizaron varias estrategias encaminadas a lograr un mejor rendimiento en el tema económico. Inicialmente, las instituciones asignarían este recurso al emprendimiento, con un control centralizado en el Estado. En términos más generales, las instituciones económicas desempeñan un papel importante para determinar si una sociedad se convierte en democracia, pero también existen otros factores relacionados con la historia y las costumbres de cada pueblo para que este desarrollo suceda. De modo que las instituciones económicas extractivas en las sociedades agrarias (por ejemplo, la esclavitud) pueden influir en los costos de la democracia para las élites no democráticas.

Frente a este tema, Moore (1966) vio la extensión del legado feudal en la agricultura como un factor clave que determina los caminos del desarrollo político. Estos legados, a raíz de la Peste Negra en Europa occidental y oriental, divergieron en el periodo moderno temprano, con profundas implicaciones para la democracia del siglo xIx. Esta democracia tampoco vio un proceso simple de modernización, con más ingresos per cápita que condujeran a una mayor democracia; 
por ello, en su esquema, solo en ciertas circunstancias específicas, la prosperidad y la democracia van juntas.

Con respecto a la conexión entre el ingreso per cápita y la democracia, también O'Donnell (1973) cuestiona esta relación argumentando que carece de poder explicativo en el contexto de América Latina, en donde, por ejemplo, las instituciones del mercado laboral fueron creadas por el estado colonial para obligar a indios y negros a trabajar en socavones en la tierra y extraer sus rentas (aunque estas instituciones persisten, han sido muy controvertidas durante las democratizaciones).

Tanto Mancur Olson (1984), en Rise and Decline of Nations, como Przeworski (2004) y Leblang (1996) sugieren que el tejido institucional del sistema político tiene un efecto final en el desarrollo económico. Olson atribuye el desempeño económico superior de las democracias a su compromiso con la protección de los derechos de propiedad, lo cual, a futuro, requiere de instituciones fuertes para mantener dichos derechos. En caso contrario, sería casi imposible contener los derechos de los más adinerados sobre aquellos más débiles.

Aunque alejados de la teoría, los más adinerados utilizan su poder para estar por encima de otros estratos, en términos generales, la élite y su configuración ayudan a definir, sumado a las variables económicas y estabilidad política, el tipo de régimen imperante en un Estado.

Si bien en algunos países del este asiático, como Corea del Sur, Taiwán y China, las estrategias para el crecimiento económico tenían como objetivo controlar las instituciones de manera eficiente, a fin de asignar capital y recursos de acuerdo con los objetivos del gobierno (Haggard, 1990), la sustentación de las políticas nacionales en torno a dicho crecimiento se sustentaban en la preparación de su recurso humano y, sobretodo, de la meritocracia, que ha sido una condición sine qua non en estos países asiáticos.

Curiosamente, no todos estos países lograron desarrollo económico y fortalecimiento de sus democracias. Por ejemplo, hoy en día, China es un país con un partido, un presidente vitalicio al mejor estilo de Mao Tse Tung, pero tiene la segunda economía más grande del mundo después de Estados Unidos. China, en condiciones autoritarias, ha desarrollado un sistema de control estatal, que brinda a su población un amplio acceso a la innovación, con una fuerte mezcla de educación en temas tecnológicos. El resultado es evidente, en la actualidad China es el país con mayor movilidad social en el mundo y ha puesto a Estados Unidos a pensar cómo contener su abrumador crecimiento económico por más de diez años seguidos. Sin embargo, China no es democrática y, contrario a lo esperado o a lo que dicen Lipset (1959a,b), Przeworski (2004), Acemoglu et al. (2019), entre otros, tal aumento en el PIB no se ha traducido en la instauración de una democracia.

\section{La democracia y el desarrollo económico}

Con su documento Political Man, Lipset (1959a) planteó la referencia del estudio entre la democracia y el nivel de desarrollo económico de un país en particular. A partir de allí, un número sustancial de científicos sociales ha teorizado y probado empíricamente teorías sobre la relación entre la democracia y el desarrollo económico. Para Huntington (1970), dicho interés se evidencia en el creciente número de estudios que exploran la relación entre democracia y desarrollo económico. Sobre esto, algunos estudiosos sostienen que el crecimiento económico impulsa la movilización social, lo que a su vez, conduce a la movilización política y, por último, al cambio de régimen a la democracia (Needler, 1968).

Por otro lado, Mainwaring \& Pérez-Liñán (2005) encuentran evidencia que muestra que la relación entre el nivel de desarrollo y la democracia, ha sido sorprendentemente indeterminado en toda América Latina, ya que en la región esta relación se presenta de forma débil. En cambio, encuentran que variables como la actitud que existía hacia la democracia y un ambiente político internacional favorable a esta, tienen una influencia decisiva en si un régimen sobrevive o quiebra. 
Ahora bien, la evidencia actual nos sitúa en una posición intermedia, pues no necesariamente existe un patrón causal entre democracia, crecimiento económico y movilización social. China, como se dijo, es uno de los países que más riqueza ha generado entre su población en los últimos 10 años. Su movilización social es envidiable y su salud económica, aunque a prueba por la administración de Trump, sigue siendo muy buena. Este país no tiene un sistema democrático, ni siquiera la producción de nuevos ricos o la creciente interdependencia económica con el mundo han hecho tambalear su sistema autocrático, contrario a esto y a los vientos revolucionarios que tocan las puertas de otras naciones, su líder ha logrado perpetuarse en el poder.

Por ejemplo, durante la administración del presidente estadounidense Barak Obama, la expectativa, en apariencia aupada por la predicción de Lipset y sus seguidores, era que el coloso asiático empezaría a mutar en un país democrático, cuya población empezaría a presionar a los tomadores de decisiones y, como resultado, un nuevo régimen democrático afloraría. Sin embargo, la predicción de Obama estaba lejos de hacerse realidad ${ }^{7}$. Por el contrario, como lo asegura King et al.(2013), el Estado chino ha mejorado sus sistemas tecnológicos de censura y las empresas privadas de vigilancia cibernética se han multiplicado, alejando la esperanza democrática mientras su economía sigue repuntando y atemorizando más a los estadounidenses.

El tema democracia y crecimiento económico es una trampa que, con el tiempo, ha desviado la atención sobre otros factores generadores de bienestar. Por fortuna, como se ha visto, otros académicos, han cuestionado esa relación sistemática entre el desarrollo económico y la democracia, por dos razones:

1. El desarrollo económico no necesariamente conduce a niveles más altos de democracia, ya que la democratización se ve afectada por múltiples factores.

7 En el 2013, un memorando interno del Partido Comunista, conocido como Documento N. ${ }^{\circ}$ 9, advirtió explícitamente contra la "democracia constitucional occidental" y otros "valores universales", como caballos de acecho destinados a debilitar, desestabilizar e incluso romper China.
2. Vinculada a la razón anterior, un gobierno democrático por sí solo puede tener un impacto limitado en el desarrollo económico, lograr consensos es más difícil y asegurar políticas estatales a largo plazo, se convierte en un reto para el partido de gobierno.

Ahora bien, existe otra forma de asegurar el matrimonio entre democracia y crecimiento, por medio del tiempo. Ante esto, Acemoglu et al. (2019) afirman que la democracia causa dicho crecimiento únicamente cuando es a largo plazo. La evidencia la sustentan en un estudio que abarcó a un grupo de países, entre 1960 y el 2010, y cuyos resultados demostraron esa afirmación al asegurar que un país que cambia de la no democracia a la democracia, logra un PIB per cápita con un $20 \%$ más alto a largo plazo. Así, llegan a la conclusión de que en los países con un PIB per cápita inferior a \$1.000uSD, su democracia podría sucumbir dentro de los siguientes 12 años. Si este está entre $\$ 1.001$ y $\$ 3.000$ usD, su duración subía aproximadamente a 20 años, y si el guarismo era mayor a $\$ 6.000$ usD, la democracia duraría indefinidamente. A conclusiones similares había llegado Przeworski en su libro Democracia y mercado (1991). Empero, embarcarse en este tipo de conclusiones es un riesgo, ya que los autores aseguran que solo las economías fuertes pueden mantener una democracia estable, cuando otros factores y ejemplos, ya citados, nos ponen a pensar en opciones diferentes.

El impacto del crecimiento económico en la supervivencia de la democracia es difícil de determinar, debido a que los patrones empíricos muestran que la democracia es más frágil en países donde el ingreso per cápita se estanca o disminuye. Sin embargo, en los pocos casos para los que hay datos comparables disponibles, las democracias tienen más probabilidades de sobrevivir cuando el coeficiente de Gini o la proporción de ingresos del quintil de arriba a abajo son más bajos, lo cual ha sido probado por autores en el mundo de la irenología, como Gurr, Skocpol, Moore y Collier, para quienes la privación y la distancia entre personas con y sin recursos económicos, es una de las varias razones para levantarse contra un régimen. Por lo que, 
mientras esa distancia no llegue a unos niveles "justos", no habrá motivo alguno para preocuparse, pues el statu quo no variaría y las mismas instituciones políticas extractivas se mantendrán.

\section{Conclusiones}

Las predicciones realizadas por Lipset (1959a,b; 2001) sobre la relación entre democracia y crecimiento económico son interesantes y válidas hoy en día, dado que si bien, en muchos de los casos el desarrollo económico pavimenta el camino para una democracia estable y fuerte, no todos los países que se han desarrollado han cambiado a regímenes democráticos. Este estudio de Lipset es seminal y un referente para muchos de sus colegas, lo cual ha permitido crear numerosos grupos de académicos, alineados en diferentes esquinas del campo. Por un lado, Sirowy \& Inkele (1990), Barro (1996), Acemoglu \& Robinson (2012); y por otro, Feng (1997), Helliwell (1994), Nelson \& Singh (1998), quienes no se han puesto de acuerdo entre si existe o no una correlación entre democracia y crecimiento económico y viceversa. En consecuencia, la falta de consenso denota una característica muy marcada en teóricos de las ciencias sociales. De igual manera, este tema, contrario a lo pensado, sigue siendo un campo de "batalla" académica permanente.

Pocos académicos como Acemoglu \& Robinson (2014), han profundizado en la importancia de las instituciones y cómo estas permiten predecir el crecimiento o no de una economía, y el fortalecimiento o no de la democracia. Para ellos, el tipo de instituciones políticas y económicas determinan un ciclo virtuoso (de existir buenas prácticas), lo que, al final, permite un crecimiento económico, sin hacer un giro a la democracia, luego de alcanzar altos niveles de bienestar (el ciclo vicioso, contrario al virtuoso, traería pobreza y explotación). Más adelante, las instituciones son más importantes que la relación entre democracia y crecimiento económico, ya que, unas instituciones sustentadas en el control estatal, y despegadas de tradiciones retrógradas, como la esclavitud, la corrupción, el clientelismo y otros males producidos por la sociedad, pueden asegurar progreso a sus ciudadanos, ya sea desde esquinas democráticas o autocráticas.

En consecuencia, dentro de este diseño institucional, uno de los lastres más pesados en el desarrollo de los estados es el path dependence que, sin llegar a ser una excusa para el desarrollo de los países, requiere de una evolución social para que las espirales de violencia no se sigan repitiendo en la actualidad. No hay que ir tan lejos para poder concluir que algunas costumbres e instituciones heredadas de la colonia aún permanecen arraigadas en muchos países y regiones. Ello, termina beneficiando a una pequeña élite supeditada a unas instituciones políticas y económicas extractivas, las cuales ayudan a mantener el statu quo de un pequeño grupo privilegiado.

A partir de esto surge la cuestión: ¿por qué países con buenos niveles de desarrollo económico, por ejemplo Estados Unidos, Francia e Inglaterra, están dando paso a alternativas anti sistema, líderes populistas y prácticas iliberales o desdemocratizadoras? Parece que la preocupación se centró tanto en los países en "vía de desarrollo" y en las nacientes democracias de la tercera ola, que se dio por sentada la estabilidad de las democracias "desarrolladas", y la realidad contemporánea da evidencias de que estas no están del todo exentas de transitar hacia la desdemocratización y el iliberalismo.

Por último, como reconoció Lijphart (2001) "sería difícil identificar un factor único", así que, establecer una relación dominante entre que si fue primero el huevo o la gallina es casi imposible. Muchos se atreven a pensar que primero deben existir las condiciones necesarias para el desarrollo económico y, por lo tanto, el huevo (la democracia) es una condición sine qua non para lograr un despegue en lo económico. Más bien, existe una causalidad múltiple de condiciones (sistema de clase abierto, riqueza económica, sistema de valores, economía capitalista, alfabetización, participación elevada en organizaciones) que tengan como posible consecuencia inicial la democracia, e incluso, puede ser que esas condiciones sean generadas por ella. 


\section{Referencias bibliográficas}

Acemoglu, D., Naidu, S., Restrepo, P., \& Robinson, J. A. (2015). Democracy, Redistribution, and Inequality. En A. Barnes \& F. Bourguignon (eds.), Handbook of income distribution (Vol. 2) (pp. 1885-1966). Elsevier. https://economics. mit.edu/files/10394

Acemoglu, D., \& Robinson, J. A. (2000). Political Losers as a Barrier to Economic Development. American Economic Review, 90(2), 126-130. https://doi.org/10.1257/aer.90. 2.126

Acemoglu, D., \& Robinson, J. A. (2012, 18 de junio). 10 Reasons Countries Fall Apart. Foreign Policy, (194), 89-91. https:// n9.cl/ygrqm

Acemoglu, D., \& Robinson, J. A. (2014). Por qué fracasan los países. Los orígenes del poder, la prosperidad y la pobreza. Revista Austral de Ciencias Sociales, 26, 139-146. https://www.redalyc.org/pdf/459/45931862008.pdf

Acemoglu, D., Naidu, S., Restrepo, P., \& Robinson, J. A. (2019). Democracy Does Cause Growth. Journal of Political Economy, 127(1), 47-100. https://doi.org/10.1086/700936

Barro, R. J. (1996). Determinants of Economic Growth: A Cross-country Empirical Study. The National Bureau of Economic Research. https://doi.org/10.3386/w5698

Baum, M. A., \& Lake, D. A. (2003). The Political Economy of Growth: Democracy and Human Capital. American Journal of Political Science, 47(2), 333-347. https://doi. org/10.1111/1540-5907.00023

Bayart, J. F. (2010). Les études postcoloniales. Un carnaval académique. Politique étrangère, (4), 912-918. https:// doi.org/10.3917/pe.104.0912.

Cardoso, F. H., \& Faletto, E. (1979). Dependency and Development in Latin America. University of California Press.

Carrero-Barón, D. (2013). Régimen de acumulación neoliberal y reconfiguración del bloque de poder: la nueva hegemonía de la burguesía financiera a propósito de las llamadas reformas estructurales a finales del siglo XX, el caso de la Asociación Nacional de Instituciones Financieras en Colombia. Instituto de Estudios Políticos y Relaciones Internacionales (IEPRI), Universidad Nacional de Colombia. https://repositorio.unal.edu.co/bitstream/handle/ unal/20689/699898-2013.pdf?sequence=1\&isAllowed=y

Cheibub, J. A., Przeworski, A., Limongi, F. P., \& Álvarez, M. M. (1996). What Makes Democracies Endure? Journal of Democracy, 7(1), 39-55. https://doi.org/10.1353/jod.199 6.0016
Feng, Y. (1997). Democracy, Political Stability and Economic Growth. British Journal of Political Science, 27(3), 391418. https://doi.org/10.1017/S0007123497000197

Haggard, S. (1990). Pathways from the Periphery: The Politics of Growth in the Newly Industrializing Countries. Cornell University Press.

Haggard, S., \& Kaufman, R. R. (2008). Development, Democracy, and Welfare States: Latin America, East Asia, and Eastern Europe. Princeton University Press.

Helliwell, J. F. (1994). Empirical Linkages Between Democracy and Economic Growth. British Journal of Political Science, 24(2), 225-248. https://doi.org/10.3386/w4066

Heo, U., \& Tan, A. C. (2001). Democracy and Economic Growth: A Causal Analysis. Comparative Politics, 33(4), 463-473. https://doi.org/10.2307/422444

Huntington, S. P. (1970). Political Order in Changing Societies. Verfassung und Recht in Übersee, VRÜ, 3(2), 257-261. https://projects.iq.harvard.edu/files/gov2126/files/hun tington_political_order_changing_soc.pdf

Kailitz, S. (2013). Classifying Political Regimes Revisited: Legitimation and Durability. Democratization, 20(1), 39-60. https://doi.org/10.1080/13510347.2013.738861

King, G., Pan, J., \& Roberts, M. E. (2013). How Censorship in China Allows Government Criticism but Silences Collective Expression. American Political Science Review, 107(2), 326-343. https://doi.org/10.1017/S0003055413000014

Krieckhaus, J. (2006). Democracy and Economic Growth: How Regional Context Influences Regime Effects. British Journal of Political Science, 36(2), 317-340. https://doi.org/10. 1017/S0007123406000172

Leblang, D. A. (1996). Property Rights, Democracy and Economic Growth. Political Research Quarterly, 49(1), 5-26. https://doi.org/10.1177/106591299604900102

Linz, J. J., \& Valenzuela, A. (Eds.). (1994). The Failure of Presidential Democracy. Comparative Perspectives (Vol 1.). Johns Hopkings University Press.

Lijphart, A. (2001). Democracy in the 21st Century: Can We Be Optimistic?. European Review, 9(2), 169-184. https://doi. org/10.1017/S1062798701000163

Lipset, S. (2001). Algunos requisitos sociales de la democracia: desarrollo económico y legitimidad. En A. Batlle (coord.), Diez textos básicos de ciencia política. Ariel.

Lipset, S. M. (1959a). Political Man: The Social Bases of Politics. Johns Hopkings University Press.

Lipset, S. M. (1959b). Some Social Requisites of Democracy: Economic Development and Political Legitimacy. American 
Political Science Review, 53(1), 69-105. https://www.js tor.org/stable/1951731

Lipset, S. M. (2016). Algunos requisitos sociales de la democracia: desarrollo económico y legitimidad política. Regímenes Políticos: orígenes y efectos, 39-94. https:// scioteca.caf.com/bitstream/handle/123456789/943/Li bro_4_CAF_2016_Vfinal_web_protect.pdf\#page $=41$

Londregan, J. B., \& Poole, K. T. (1996). Does High Income Promote Democracy? World Politics, 49(1), 1-30. https://doi. org/10.1353/wp.1996.0024

Mainwaring, S., \& Pérez-Liñán, A. (2005). Latin American democratization since 1978. The third wave of democratization in Latin America, 14-54.

Moore, B. (1966). Social Origins of Dictatorship and Democracy: Lord and Peasant in the Making of the Modern World. Beacon Press.

Monroy, G. V., \& Flores, R. P. (2009). Perspectiva de la teoría del capital humano acerca de la relación entre educación y desarrollo económico. Tiempo de educar, 10(20), 273306. https://www.redalyc.org/pdf/311/31112987002.pdf

Needler, M. C. (1968). Political Development and Socioeconomic Development: the Case of Latin America. American Political Science Review, 62(3), 889-897. https://doi. org/10.2307/1953438

Nelson, M. A., \& Singh, R. D. (1998). Democracy, Economic Freedom, Fiscal Policy and Growth in LDCs: a Fresh Look. EConomic Development and Cultural Change, 46(4), 677-696. http://dx.doi.org/10.1086/452369

Norris, P., Frank, R. W., \& i Coma, F. M. (2014). Measuring Electoral Integrity Around the World: A New Dataset. PS: Political Science \& Politics, 47(4), 789-798. https://doi. org/10.1017/S1049096514001061

O’Donnell, G. A. (1973). Modernization and Bureaucratic-authoritarianism: Studies in South American politics. University of California Intl.
Olson, M. (1945). The Varieties of Eurosclerosis: the Rise and Decline of Nations Since 1982. Economic growth in Europe since, 73-94. https://doi.org/10.1017/CBO9780511758683

Olson, M. (1984). Rise and Decline of Nations. Economic Growth, Stagflation, and Social Rigidities. Yale University Press.

Przeworski, A. (1991). Democracy and the Market: Political and Economic Reforms in Eastern Europe and Latin America. Cambridge University Press.

Przeworski, A. (2004). Institutions Matter? Government and Opposition, 39(4), 527-540. https://doi.org/10.1111/j.147 7-7053.2004.00134.x

Przeworski, A., Álvarez, R. M., Álvarez, M. E., Cheibub, J. A., \& Limongi, F. (2000). Democracy and Development: Political Institutions and Well-being in the World, 1950-1990. Cambridge University Press.

Przeworski, A., Limongi, F. P, \& Giner, S. (1995). Political Regimes and Economic Growth. En A. Kumar (ed.), Democracy and Development (pp. 3-27). Palgrave Macmillan.

Rhoden, T. F. (2015). The Liberal in Liberal Democracy. Democratization, 22(3), 560-578. https://doi.org/10.1080/1351 0347.2013.851672

Sáinz, J. P. (2019). Una historia de la desigualdad en América Latina: La barbarie de los mercados, desde el siglo XIX hasta hoy. Siglo xxı Editores.

Sirowy, L., \& Inkeles, A. (1990). The Effects of Democracy on Economic Growth and Inequality: A review. Studies in Comparative International Development, 25(1), 126-157. https://doi.org/10.1007/BF02716908

Tilly, C. (2017). War Making and State Making as Organized Crime. En E. Castañeda \& C. Schneider, Collective Violence, Contentious Politics, and Social Change (pp. 121-139). Routledge.

Wade, R. (2004). Governing the Market: Economic Theory and the Role of Government in East Asian industrialization. Princeton University Press. 